\title{
Projetando uma Solução de Segurança Baseada em Computação Vestível para Ambientes Ferroviários
}

\author{
Bruno V. Ferreira ${ }^{1,2}$, Gerson Serejo ${ }^{1}$, Mylena R. Ferreira ${ }^{1,2}$, \\ Danilo Ferreira $^{1}$, Leon Cardoso ${ }^{1}$, Ewelton Yoshidome ${ }^{1}$, Helder Arruda ${ }^{1}$, \\ Wallace Lira $^{1}$, Gustavo Pessin ${ }^{1,3}$, Cleidson R. B. Souza ${ }^{1,3}$ \\ ${ }^{1}$ Laboratório de Computação Aplicada \\ Instituto Tecnológico Vale - Belém, PA, Brasil \\ ${ }^{2}$ Instituto de Tecnologia \\ Universidade Federal do Pará (UFPA) - Belém, PA, Brasil \\ ${ }^{3}$ Instituto de Ciências Exatas e Naturais \\ Universidade Federal do Pará (UFPA) - Belém, PA, Brasil \\ bruno.ferreira@itec.ufpa.br, \{gerson.serejo, fr.mylena, danilo79, \\ engleoncardoso, ewelton.yoshio, arruda.helder, wallace.lira\}@gmail.com, \\ gustavo.pessineitv.org, cleidson.desouzalacm.org
}

\begin{abstract}
Resumo. Ferrovias provêm um meio de transporte considerado eficiente, mas que não são isentas de riscos na sua manutenção. $O$ ambiente ferroviário também está sujeito a extremos climáticos, como altas temperaturas, sol constante, chuvas e vento. Além disso, por percorrer diversas áreas sem cobertura de redes telefônicas, a comunicação entre trens e pessoas, por meio de uma central, é inviável. Desta forma, o desenvolvimento de soluções tecnológicas para aumentar a segurança dos empregados que atuam na manutenção ferroviária é um interessante problema de pesquisa a ser considerado. É justamente neste contexto que este trabalho se enquadra ao descrever uma solução baseada em componentes vestíveis para a segurança dos empregados que atuam na manutenção ferroviária. Este artigo descreve os desafios que precisaram ser considerados para o design da solução proposta considerando aspectos de usabilidade relacionados com a percepção das pessoas aos alertas tácteis, visuais e sonoros. Além disto, a proposta de solução e a avaliação de dispositivos de comunicação a fim de permitir independência de provedores de redes de dados mantendo o sistema funcional por toda a ferrovia também é descrita.
\end{abstract}

\section{Introdução}

Ferrovias provêm um meio de transporte eficiente, em geral envolvendo longos percursos que usualmente atravessam ambientes urbanizados e não-urbanizados. Como qualquer meio de transporte, existe um risco associado à passagem do veículo, seja para pessoas que estejam utilizando a via para fins impróprios ou para as equipes de manutenção. Companhias de transporte e logística estão cientes deste risco e adotam métodos para aumentar a segurança dos seus empregados e dos habitantes que vivem ao longo das vias, incluindo pessoal especialmente treinado em segurança, tecnologias (radio, câmeras, etc) e diversos procedimentos de operação [Lira et al. 2014]. 
Mesmo com grande atenção voltada para a segurança dos empregados e habitantes, alguns incidentes ainda ocorrem. Desta forma, o desenvolvimento de novas tecnologias, que tenham como objetivo aumentar a segurança são sempre desejáveis. Este artigo descreve atividades de um projeto em andamento que tem como objetivo o desenvolvimento de sistemas para minimização de riscos e aumento de eficiência em operações ferroviárias. Dois pontos cruciais na questão ferroviária são: (i) a falta de cobertura de comunicação digital em diversos trechos, o que impossibilita o tracking constante de funcionários e veículos, e (ii) o ambiente de manutenção de ferrovia é sujeito a extremos climáticos, como altas temperaturas, sol constante, chuvas e vento. Assim, este artigo apresenta a proposta, o desenvolvimento e a avaliação de uma solução baseada em componentes vestíveis considerando duas frentes de trabalho: (i) investigações de aspectos de usabilidade relacionados com a percepção das pessoas aos alertas tácteis, visuais e sonoros fornecidos pelo componente vestível e (ii) a proposta e avaliação de dispositivos de comunicação a fim de permitir independência de provedores de redes de dados mantendo o sistema funcional por toda a ferrovia. Ao apresentar estes dois aspectos, este artigo contribui para os desafios que precisam ser enfrentados para o desenvolvimento de soluções vestíveis em ambientes de trabalho não convencionais, isto é, com diversas limitações de infra-estrutura e ambientais.

Este artigo está estruturado da seguinte forma: A Seção 2 apresenta a descrição do ambiente ferroviário, considerado de risco, e a proposta para aumento de segurança. Nas Seções 3 e 4 são apresentados respectivamente os conceitos de percepção e as alternativas de design consideradas, bem como a solução escolhida. Na Seção 5 apresentamos as tecnologias utilizadas para endereçar o problema de comunicação; seguido pela Seção 6 que apresenta os resultados de avaliações com os atuais protótipos, considerando o alcance e a qualidade da comunicação. O artigo é finalizado com a apresentação de conclusões e dos trabalhos futuros vislumbrados.

\section{O Ambiente de Risco e a Proposta para Aumento de Segurança}

A Figura 1(a) apresenta um exemplo do ambiente considerado como situação de risco. Existem duas vias férreas paralelas; uma delas é bloqueada para operação de manutenção, enquanto a outra linha permanece disponível para passagem de trem. Ainda, na parte inferior direita da imagem, podemos ver uma estrada de terra que também pode ser foco de risco devido a passagem de veículos de transporte ou carga. Uma das dificuldades atuais é manter comunicação entre trem e pessoas por todo o percurso. Dessa forma, propomos o esquema apresentado na Figura 1(b). Neste esquema, temos um dispositivo emissor posicionado na locomotiva, e um dispositivo receptor em cada funcionário (como pode ser visto na Figura 2). O dispositivo emissor, posicionado na locomotiva, é composto por um rádio (detalhado na Seção 5) e um GPS. O GPS é responsável pela obtenção dos atributos de posição (latitude, longitude, erro estimado), velocidade, e tempo. O rádio deve fazer broadcast da posição a cada meio segundo $(2 \mathrm{~Hz})$. Avaliações iniciais, fora do escopo deste artigo, buscaram avaliar distância por meio de intensidade de sinal (RSSI) no lugar do GPS. Entretanto, para o ambiente proposto, os resultados de intensidade de sinal por meio do rádio utilizado se mostraram instáveis, não permitindo obter distância com a precisão esperada (erro inferior a 20 metros). Dessa forma, a localização por GPS apresenta maior confiabilidade e menor erro, embora aumente os custos tanto financeiros como de consumo de energia do sistema. 


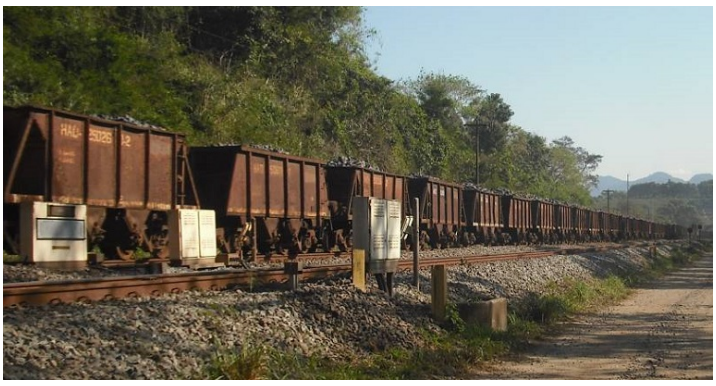

(a)

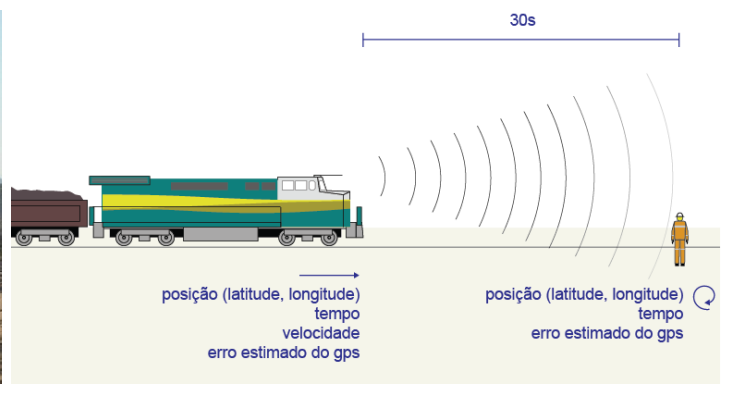

(b)

Figura 1. (a) Trem passando em uma linha sem bloqueio enquanto a outra linha estava bloqueada para manutenção. A foto ainda apresenta uma estrada de terra auxiliar (a direita) que pode também ser foco de risco dada a passagem de outros veículos. (b) Esquema proposto, considerando dispositivo emissor no trem e receptor com atuação de alerta em cada funcionário (ver Figura 2).

O dispositivo receptor (Figura 2), posicionado em cada empregado, também é composto por um rádio, um GPS e por três mecanismos de atuação: sonoro, luminoso e vibratório. O GPS é responsável pela obtenção dos atributos locais de posição (latitude, longitude, erro estimado), e tempo. O rádio deve fazer continuamente busca por sinais em sua área de alcance. Ao receber um pacote de dados proveniente do trem (por este entrar no raio de alcance), o cálculo entre as duas posições (a do trem e a do receptor) e velocidade é realizado a fim de que os alertas sejam disparados quando o trem esteja a, pelo menos, 30 segundos da posição do empregado. Leva-se em conta a velocidade, e não a distância, pelo motivo dos trens serem extremamente heterogêneos tanto em termos de carga como de velocidade permitida. Por exemplo, existem trens que trafegam a $40 \mathrm{~km} / \mathrm{h}$ (vagão antigo, com carga de minério) enquanto outros trens podem chegar a $90 \mathrm{~km} / \mathrm{h}$ (trem de passageiros).

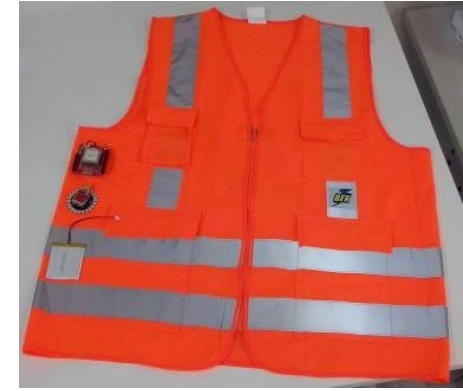

(a)

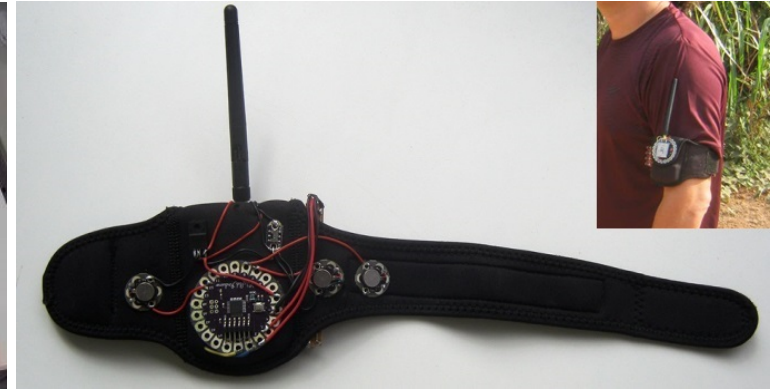

(b)

Figura 2. (a) Exemplo de hardware em avaliação. Podemos ver uma bateria, um shield GPS para Arduino, uma placa LillyPad e sua comparação de tamanho com o colete utilizado na ferrovia. (b) Braçadeira desenvolvida com 3 dispositivos de vibração.

A Figura 2(a) apresenta um exemplo de dispositivo vestível em avaliação. Podemos ver uma bateria, um shield GPS para Arduino, uma placa LillyPad e sua comparação de tamanho com o colete utilizado na ferrovia. A Figura 2(b) apresenta a braçadeira desenvolvida com 3 dispositivos de vibração. Os resultados das avaliações serão descritos na Seção 6. 


\section{Conceitos de Percepção}

Nesta seção são discutidos os aspectos de usabilidade relacionados com a percepção das pessoas aos alertas sonoros, visuais e vibratórios fornecidos pelo componente vestível desenvolvido. Em especial, os desafios associados com o design destes alertas são apresentados uma vez que a solução desenvolvida será utilizada em ambientes de trabalho não convencionais, isto é, com limitações ambientais e de infra-estrutura. Os desafios são discutidos no contexto dos trabalhos relacionados identificados.

Percepção é a organização, identificação e interpretação de informações sensoriais para representar e entender o ambiente. As primeiras observações de pesquisadores da área da psicofísica estabelecem o limite de percepção sensorial que consiste na diferença mínima entre dois estímulos para que seja discriminada alguma diferença entre eles [Kandel et al. 2000]. Ou seja, no contexto da solução vestível sendo desenvolvida, a percepção é importante pois indicará aos empregados a existência, ou não, de uma situação de risco. A percepção tátil é um desafio que precisa ser tratado quando se considera que os empregados que utilizarão a solução vestível realizam trabalho físico pesado e roupas de proteção específicas. Ligada à percepção tátil está a sensação de conforto físico, especialmente no que se refere ao conforto térmico, ao controle de umidade, à mobilidade, à flexibilidade e ao ajuste de tamanho [Dunne 2004]. Atualmente, a vibração é o feedback tátil mais comum em interfaces homem-máquina, a exemplo de celulares e videogames. Outras percepções táteis além da vibração seriam: pressão, textura, alongamento e contração, temperatura, dor e posição corporal. [Karuei et al. 2011] fizeram um experimento colocando atuadores de vibração (piezo-elétricos de massa excêntrica com $5 \mathrm{kHz}$ de frequência) em 13 locais do corpo, de acordo com a Figura 3 . O experimento verificou a influência de: movimento do corpo (ao andar em esteira), gênero, intensidade da vibração, distração visual e expectativa antecipada. Na primeira parte do experimento, os atuadores de vibração poderiam vibrar em qualquer um dos 13 locais, de forma aleatória. $\mathrm{Na}$ segunda parte, 9 locais mais promissores foram escolhidos e o participante do experimento sabia antecipadamente que local iria vibrar. Durante os testes, para a distração visual foi colocado uma projeção em um telão. Nesta projeção apareciam vinte e cinco cubos coloridos e numerados de 1 a 5 se movimentando dentro de um espaço tridimensional. Os participantes deveriam contar quantas vezes um determinado bloco colidia com outro e com as paredes do espaço. A intenção era simular a carga mental de um pedestre mantendo atenção a pessoas e carros.

De um modo geral, os resultados do estudo de [Karuei et al. 2011] são os seguintes: os pulsos e a coluna são os locais mais sensíveis a vibração, com braços em seguida. Os piores locais são os pés e as coxas. Além disso, a movimentação do corpo ao andar reduz a taxa de percepção e aumenta o tempo de reação mesmo em altas intensidades, principalmente para pés e coxas. A distração visual não teve efeito significativo nos resultados. Há ainda a ser considerado que, com um estímulo constante, os mecanoreceptores vão gradualmente aumentando seu limite de percepção sensorial. Idealmente, o alerta tátil não pode durar mais que 6 minutos. Deverá então haver uma forma de seguramente (não acidentalmente) desarmar o alerta pois algo vibrando por mais que poucos segundos pode facilmente se tornar um incômodo. É importante citar o trabalho de [Karuei et al. 2011], pois ele é um dos poucos que discute aspectos relevantes para a solução em desenvolvimento, ou seja, os trabalhos sobre percepção, no contexto de computação vestível, em ambientes de trabalho reais e com condições climáticas extremas ainda são praticamente 

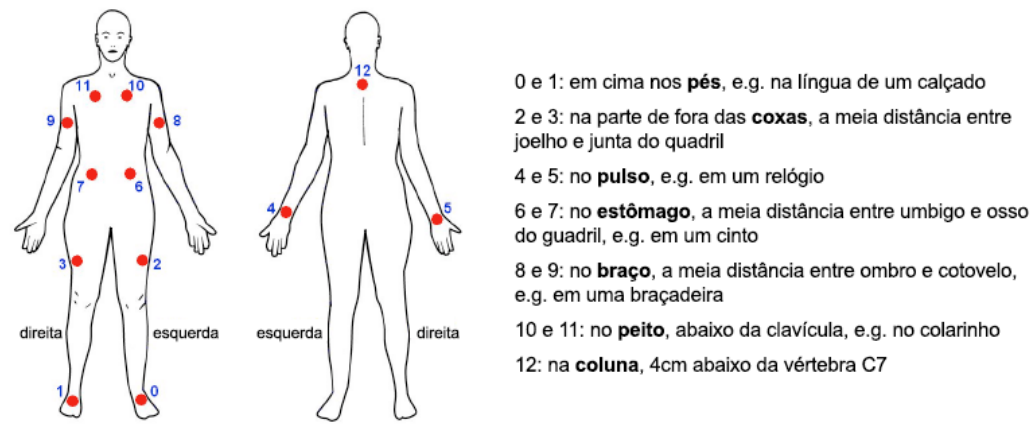

Figura 3. Localizações utilizadas dos atuadores de vibração nos experimentos de [Karuei et al. 2011].

inexistentes.

O maior desafio em relação a percepção visual é a percepção do alerta luminoso na luz do dia, em posição que pode estar frequentemente fora do campo visual do empregado. $\mathrm{O}$ aviso visual pode ser percebido graças ao contraste de luminância ou de cor. Com a solução vestível no pulso ou braço, e dependendo do trabalho sendo executado pelo usuário, podem ocorrer situações em que o alerta visual não esteja dentro do campo de visão. Por outro lado, o alerta se torna principalmente funcional para demais pessoas próximas ao empregado. A opção de uso de fonte luminosa por LEDs se dá por causa da eficiência energética dos mesmos, do seu tamanho reduzido, sua longa vida útil e da resistência a choque e vibração. De acordo com [Sivak 1998], testes de laboratório indicam que um incremento mínimo de cerca de $8 \%$ sobre a luminância de fundo é necessário para que um estímulo seja percebido. Para [Pervic et al. 2005], esse incremento fica entre 1 e $7 \%$, dependendo da luminância do ambiente. Dado que a luz do sol é muito intensa, seria necessário o uso de um arranjo de LEDs de alta potência, que poderiam consumir até 1 A e necessitariam de dissipadores de calor. Se o calor não é removido de um LED de alta potência, ele pode falhar em questão de segundos, ou, se removido de forma não adequada, pode ter sua eficiência luminosa e vida útil reduzidas. Como um dissipador de calor em uma solução vestível não é algo interessante, assim como também não é o uso de centenas de LEDs mais fracos, a cor se torna um fator importante para a percepção visual, tanto ou mais que o brilho. [Wogalter et al. 1998] fizeram testes comparativos com estímulos coloridos e descobriram que o vermelho foi considerado significativamente maior indicativo de risco que outras cores. Em segundo lugar viria o amarelo. Por outro lado, na visão periférica extrema, os olhos humanos não captam bem as cores, podendo identificar com menor distorção o azul e o amarelo [Panorgias et al. 2012]. Após cerca de 20 graus do centro da visão, um estímulo vermelho e principalmente o verde sofrem significativa alteração em tom e saturação.

O maior desafio em relação a percepção sonora se dá pelo fato dos empregados que atuam na manutenção ferroviária utilizarem abafadores de ruído. Estes abafadores são necessários devido a regulamentações trabalhistas e podem atenuar tanto alarmes como outros avisos sonoros. Logo, é importante saber que tipo de som apresenta a forma ideal como alarme. Para isso, faz-se necessário avaliar o EPI utilizado, empregando técnicas eficazes de medição [Berger 2005]. O ouvido humano é capaz de perceber frequências 
entre 20 e $20.000 \mathrm{~Hz}$, no entanto além da frequência sonora, a pressão sonora também deve ser levada em consideração para distinguir os sons audíveis, os inaudíveis e aqueles que são desconfortáveis para os ouvidos, podendo inclusive deixar sequelas. Para mensurar os níveis sonoros, podem ser utilizadas escalas logarítmicas chamadas de Escalas de Decibels (dB). Filtros de ponderação representados pelas letras A, B e C são utilizados pelos decibelímetros para representar diferentes níveis de intensidade, podendo a escala ser representada por $\mathrm{dB}(\mathrm{A})=40$ fons, $\mathrm{dB}(\mathrm{B})=70$ fons e $\mathrm{dB}(\mathrm{C})=100$ fons [Frota 2003]. A eficiência de alertas sonoros está associada a três fatores: ao fato do alerta conseguir ser detectado, de atrair atenção e de ser distinguido entre os outros sons do ambiente.

\section{Usabilidade e Percepção}

Esta seção descreve os diferentes designs que foram considerados durante o processo de tomada de decisão em relação a solução proposta. Para cada um dos diferentes designs, foram conduzidas avaliações de usabilidade que tinham como objetivo verificar a eficiência dos estímulos visual, sonoro e tátil, sendo relacionados, respectivamente, como luz (LED), alarme e vibração em três equipamentos: colete, capacete e braçadeira.

A primeira opção de design considerou um colete que foi equipado com LEDs de pouca intensidade, de cor branca. $\mathrm{O}$ teste com este colete foi realizado em dois cenários: na sombra e sob a luz do sol. O uso de LEDs brancos em um ambiente com sombra mostrou-se eficiente. Entretanto, sob a luz do sol, percebeu-se uma queda considerável na visibilidade da luz emitida pelo LED. Salienta-se que nos dois cenários de testes, a luz emitida não é facilmente visível para o usuário do colete, por estar muitas vezes fora do campo de visão. Assim, pode-se concluir que os LEDs do colete são mais eficientes para alertar as pessoas que estão nas proximidades do usuário.

A segunda opção de design considerou um capacete que foi equipado com um único de LED de cor vermelha, localizada na aba. A cor foi escolhida conforme teste preliminar e por ser consagrada como cor de alerta, tal como discutido na Seção 3. O teste com o capacete foi realizado novamente em dois cenários: na sombra e sob a luz do sol. A luz do LED do capacete em um ambiente com sombra possui uma visibilidade moderada. Quando o teste foi realizado em um ambiente iluminado (sob o sol), notouse uma perda na visibilidade da luz do LED, tornando muito difícil a sua percepção. A vantagem do capacete é que ele poderia facilitar a percepção sonora por ser utilizado próximo aos abafadores de ruído. Por outro lado, capacetes tradicionalmente usados por equipes de manutenção possuem restrições de modificação por questões de segurança.

Assim, a terceira opção de design, que são braçadeiras, foi a solução considerada mais adequada. As braçadeiras permitem o uso dos três modais de alerta táctil, visual e sonoro de forma menos restritiva. A braçadeira é então composta por um conjunto de LEDs brancos e vermelhos, três atuadores de vibração e um alarme. Neste caso, três cenários de teste foram definidos: teste de percepção visual, sonoro e tátil. Durante o teste de percepção visual, a luz branca emitida se mostrou ineficiente sob a luz do sol. Os LEDs vermelhos eram mais fáceis de serem percebidos sob o sol. Entretanto, a cerca de $15 \mathrm{~m}$ de distância não era possível ver os LEDs piscando sob a luz do sol mesmo com o empregado imóvel. Na sombra, os LEDs mostraram-se mais eficientes, especialmente os brancos. Ainda assim, deve-se salientar que o usuário não conseguia visualizar as luzes quando seu braço estava em repouso. Também foi realizado um teste de percepção sonoro. 
Neste teste, foi verificado se era possível escutar o alarme com e sem interferência sonora no ambiente. $\mathrm{O}$ alarme mostrou-se eficaz até uma distância aproximada de $15 \mathrm{~m}$. Porém, quando eventuais veículos passavam próximo do usuário, as pessoas nas proximidades não conseguiam escutar o alarme. Finalmente, no teste de percepção, notou-se que o estímulo tátil era bastante eficiente. Entretanto, quando o usuário executava uma atividade pesada que envolvesse o uso do braço, o estímulo tátil se tornava quase imperceptível.

Os resultados acima ilustram de maneira clara quão desafiador é o design de uma solução vestível para um ambiente hostil como as ferrovias: nenhuma das três soluções se mostrou completamente adequada para o ambiente identificado. Além disso, não foi possível encontrar literatura que apresentasse de maneira inequívoca resposta para os desafios enfrentados.

\section{Tecnologias Utilizadas para Comunicação}

Dentre os desafios de comunicação, encontram-se os seguintes fatores: (i) distância de pelo menos um quilômetro de alcance de comunicação, (ii) possibilidade de criação de redes mesh altamente dinâmicas, (iii) baixo consumo de energia, e finalmente, (iv) facilidade de uso por parte dos operadores. As ferrovias da Vale tem um sistema conhecido como "sistema de sinalização" que permite conhecer a posição do trem por meio de um curto circuito na linha férrea. Tal sistema permite a uma central de operação identificar a posição do trem, entretanto, este sistema possui limitações como por exemplo, a alta granularidade, ou seja, o trem pode estar localizado em um trecho 2 a 3 vezes maior que o mesmo. Além disso, este sistema não está instalado em todas as ferrovias e depende de instalação de um sistema de controle sofisticado. Um problema com essa abordagem é o não conhecimento da localização das pessoas, como por exemplo, os empregados da empresa. Outro problema seria a falta de comunicação entre a central e as equipes de manutenção a fim de transmitir informações devido as inúmeras áreas sem cobertura de transmissão de dados.

O uso de redes de transmissão de dados de operadoras de telefonia celular é inviável devido a existências de diversas áreas sem cobertura. Caso existisse cobertura, avaliações sobre a disponibilidade e qualidade das transmissões deveriam ser realizadas. Dessa forma, imaginou-se o sistema operando com um sistema de comunicação sem fio ad hoc entre os trens e as pessoas. Alternativas como WiFi ou Bluetooth, embora com características de comunicação aceitáveis, apresentam limitações de alcance. WiFi tem, em geral, alcance de 100 metros e alto consumo de energia. Bluetooth, embora com baixo consumo de energia, apresenta maior limitação de alcance, em geral de 10 metros. Alternativas como RFID apresentam as menores taxas de consumo de energia, embora a distância das antenas seja, no máximo, de 40 metros. Assim, uma alternativa que parece razoável é o protocolo ZigBee implementado por meio de placas xBee Series 2 e 3. O xBee Series 1 não permite redes mesh, por isso das alternativas de Series 2 e 3. Algumas configurações de xBee permitem alcance superior a um quilômetro e tem baixo consumo de energia se comparado ao WiFi. Uma limitação do ZigBee seria a baixa taxa de transmissão de dados, embora, para nosso contexto, como a transmissão é de poucos dados, essa limitação não se aplica. Dessa forma, escolhemos as configurações de xBee Series 2 e 3 para as avaliações apresentadas na Seção 6. 


\section{Avaliações sobre Alcance e Qualidade da Comunicação}

Os dispositivos escolhidos para a avaliação de alcance e qualidade da comunicação foram dispositivos que implementam o protocolo ZigBee. Os dispositivos são o xBee Series 2, que opera na faixa de frequência de $2.4 \mathrm{GHz}$ e o xBee Series 3, que opera na faixa de frequência de $900 \mathrm{MHz}$. Ambos apresentam a capacidade de criação de redes mesh dinâmicas. As Figuras 4(a) e 4(b) apresentam o ambiente de testes, considerando diferentes distâncias entre base emissora e receptora. Em uma primeira avaliação, nitidamente, a posição da antena, mais perto ou mais afastada do solo permite, respectivamente, menor ou maior recepção do sinal. Assim, neste teste, definimos a posição da base emissora a aproximadamente 2 metros do solo e a base receptora na altura do ombro de um possível usuário $(\approx 1,60$ metros $)$. Considerando que a altura da locomotiva é maior, é esperada uma melhor propagação do sinal, com menor reflexão do solo. Cerca de dois minutos de leitura foram realizados em cada configuração de distância/antenas permitindo a obtenção de cerca de 60 leituras por ponto (um pacote a cada dois segundos). Para ambos os testes, de 200 a 800 metros, temos visada clara (ver Figuras 4(a) e 4(b)), entretanto para 1000 metros a visada direta não era possível.

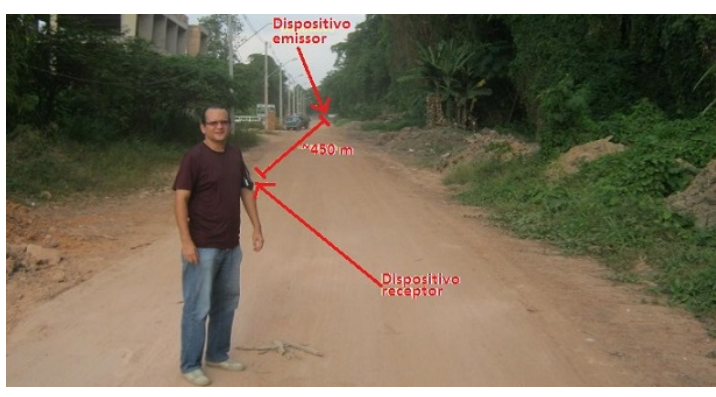

(a)

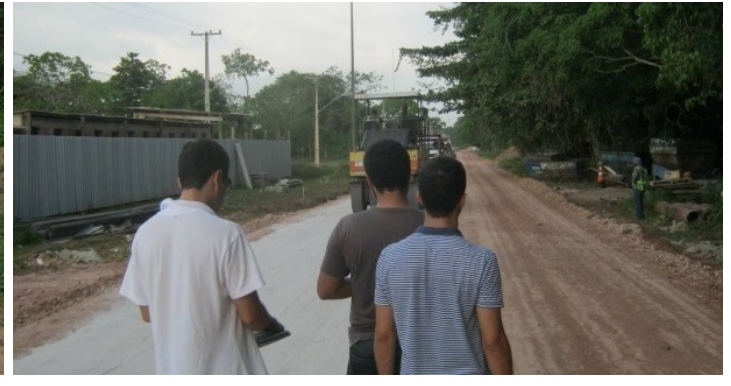

(b)

Figura 4. Ambiente de testes. (a) Distância entre base emissora e receptora de $\approx$ 450 metros. Distância entre base emissora e receptora de $\approx 800$ metros. Ainda é possível ter contato visual entre a base emissora e receptora. Obstáculos móveis são visíveis no trajeto.

As antenas utilizadas são específicas para a faixa de operação de cada versão do xBee (900 MHz ou $2.4 \mathrm{GHz}$ ) e podem ser vistas nas Figuras 5 e 6 . A avaliação realizada considerou duas configurações de antena para casa versão de xBee e quatro pontos de distância $\{200,500,800$, e $1000 \mathrm{~m}\}$ entre a base emissora e receptora. As configurações de antenas e distâncias, bem como o número de perda de pacotes, podem ser vistas nas Tabelas 1 e 2 .

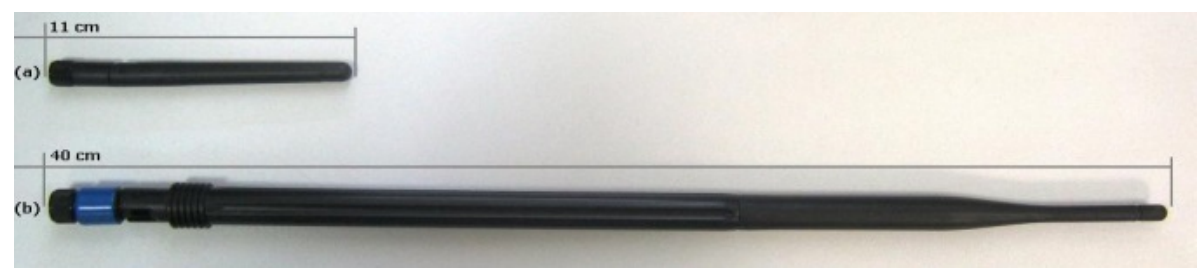

Figura 5. Exemplo de antenas avaliadas para a faixa de freqüência de $2.4 \mathrm{GHz}$ (xBee Series 2). (a) Antena com ganho de $2 \mathrm{dBi}$. (b) Antena com ganho de 25 dBi. 


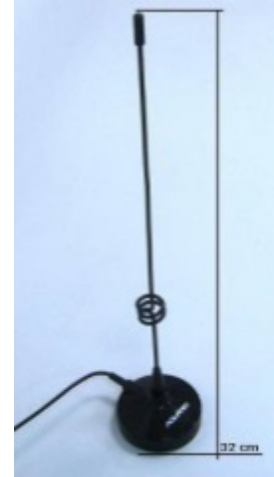

(a)

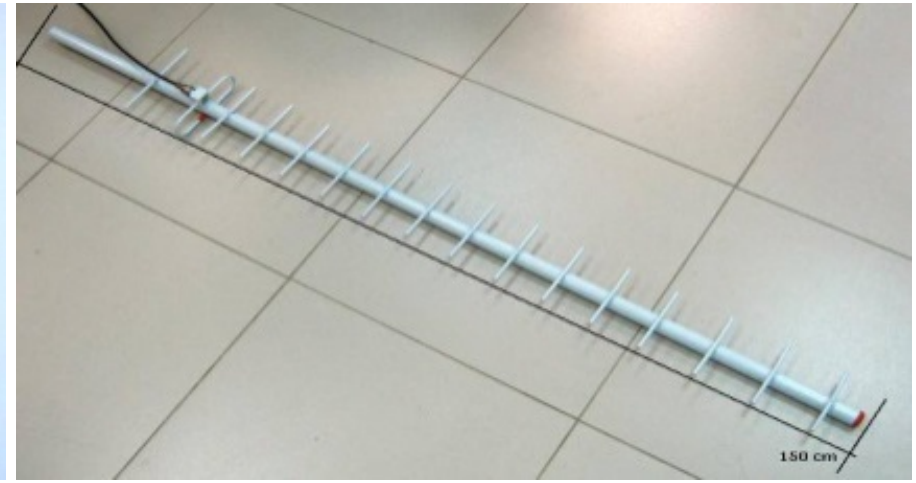

(b)

Figura 6. Exemplo de antenas avaliadas para a faixa de freqüência de $900 \mathrm{MHz}$ (xBee Series 3). (a) Antena com ganho de $7 \mathrm{dBi}$. (b) Antena com ganho de $17 \mathrm{dBi}$.

Tabela 1. Resultados de perda de pacotes usando o xBee Series $2(2.4 \mathrm{GHz}$, utilizando as antenas apresentadas na a Figura 5).

\begin{tabular}{rrrrrrrrr}
\hline & \multicolumn{7}{c}{ Distância entre receptor e emissor } & \multicolumn{2}{c}{$1000 \mathrm{~m}$} \\
\hline Receptor (ganho) & $200 \mathrm{dBi}$ & $9 \mathrm{dBi}$ & $2 \mathrm{dBi}$ & $9 \mathrm{dBi}$ & $2 \mathrm{dBi}$ & $9 \mathrm{dBi}$ & $2 \mathrm{dBi}$ & $9 \mathrm{dBi}$ \\
Emissor (ganho) & $25 \mathrm{dBi}$ & $25 \mathrm{dBi}$ & $25 \mathrm{dBi}$ & $25 \mathrm{dBi}$ & $25 \mathrm{dBi}$ & $25 \mathrm{dBi}$ & $25 \mathrm{dBi}$ & $25 \mathrm{dBi}$ \\
Perda de pacotes & $0,00 \%$ & $0,00 \%$ & $0,00 \%$ & $0,00 \%$ & $2,94 \%$ & $0,00 \%$ & $14,28 \%$ & $12,50 \%$ \\
RSSI (média) & $-56,4$ & $-59,4$ & $-77,7$ & $-73,1$ & $-88,0$ & $-87,0$ & $-94,9$ & $-93,8$ \\
RSSI (desvio) & 3,0 & 6,6 & 4,2 & 4,6 & 3,8 & 4,1 & 2,7 & 2,9 \\
\hline
\end{tabular}

Podemos ver na Tabela 1 (usando $2.4 \mathrm{GHz}$ ) que temos mais perdas de pacotes que na Tabela 2 (usando $900 \mathrm{MHz}$ ). Embora a perda não seja muito grande, ela ocorre na faixa de 800 e 1000 metros. Ainda, por contarmos com objetos móveis fora do nosso controle na via, é possível que a perda de pacotes tenha sido devido a configuração dos objetos (caminhões na via). Nesta configuração, também podemos ver que como esperado, o RSSI diminui de acordo com a distância. Na Tabela 2, podemos ver que a única perda de pacote registrada foi com a distância de $1 \mathrm{~km}$ entre base emissora e receptora usando a antena com menor ganho $(7 \mathrm{dBi})$. Nenhuma perda de pacote foi registrada quando o conjunto de antenas foi 17-17. Como esperado, o RSSI também diminui de acordo com a distância. Pelo RSSI ainda podemos ver que a antena de $17 \mathrm{dBi}$ apresenta sempre melhores resultados que a antena de $7 \mathrm{dBi}$.

\section{Conclusões e Trabalhos Futuros}

Neste artigo buscamos descrever desafios que precisam ser considerados para o design de uma solução tecnológica para aumentar a segurança dos empregados que atuam na manutenção ferroviária. A proposta considera aspectos de usabilidade relacionando-os

Tabela 2. Resultados de perda de pacotes usando o xBee Series $3(900 \mathrm{MHz}$, utilizando as antenas apresentadas na Figura 6).

\begin{tabular}{rrrrrrrrr}
\hline & \multicolumn{7}{c}{ Distância entre receptor e emissor } \\
& \multicolumn{2}{c}{$200 \mathrm{~m}$} & \multicolumn{2}{c}{$500 \mathrm{~m}$} & \multicolumn{2}{c}{$800 \mathrm{~m}$} & \multicolumn{1}{c}{$1000 \mathrm{~m}$} \\
\hline Receptor (ganho) & $7 \mathrm{dBi}$ & $17 \mathrm{dBi}$ & $7 \mathrm{dBi}$ & $17 \mathrm{dBi}$ & $7 \mathrm{dBi}$ & $17 \mathrm{dBi}$ & $7 \mathrm{dBi}$ & $17 \mathrm{dBi}$ \\
Emissor (ganho) & $17 \mathrm{dBi}$ & $17 \mathrm{dBi}$ & $17 \mathrm{dBi}$ & $17 \mathrm{dBi}$ & $17 \mathrm{dBi}$ & $17 \mathrm{dBi}$ & $17 \mathrm{dBi}$ & $17 \mathrm{dBi}$ \\
Perda de pacotes & $0,00 \%$ & $0,00 \%$ & $0,00 \%$ & $0,00 \%$ & $0,00 \%$ & $0,00 \%$ & $2,38 \%$ & $0,00 \%$ \\
RSSI (média) & $-43,6$ & $-40,0$ & $-56,1$ & $-40,1$ & $-74,7$ & $-45,4$ & $-81,1$ & $-62,2$ \\
RSSI (desvio) & 6,1 & 0,0 & 7,9 & 0,7 & 5,2 & 2,4 & 3,6 & 1,9 \\
\hline
\end{tabular}


com a percepção das pessoas aos alertas tácteis, visuais e sonoros. Além disto, investigamos dispositivos de comunicação a fim de permitir independência de provedores de redes de dados mantendo o sistema funcional por toda a ferrovia.

Alguns pontos que merecem destaques para futuras investigações envolvem o uso dos dispositivos no ambiente ferroviário propriamente dito. Nas investigações realizadas, antenas rígidas foram empregadas; o que é possível de utilização na locomotiva, entretanto, do lado dos usuários, avaliações com antenas flexíveis devem ser preferíveis. Outro ponto que merece destaque são as frequências utilizadas, nas faixas de $900 \mathrm{MHz}$ e $2.4 \mathrm{GHz}$. Devem ser avaliadas características de comunicação considerando possíveis pontos de interferência ou licenciamento específico de alguma outra faixa de frequência a ser empregada. E então, um teste de cobertura no ambiente real deve ser realizado.

\section{Agradecimentos}

Os autores gostariam de agradecer ao apoio financeiro recebido através da Chamada 59/2013 MCTI/CT-Info/CNPq, processo 440880/2013-0.

\section{Referências}

Berger, E. H. (2005). Preferred methods for measuring hearing protector attenuation. In Proceedings of Inter-Noise, volume 5, page 58.

Dunne, L. E. (2004). The design of wearable technology: addressing the human-device interface through functional apparel design. PhD thesis, Cornell University.

Frota, S. (2003). Fundamentos em fonoaudiologia: audiologia.

Kandel, E. R., Schwartz, J. H., Jessell, T. M., et al. (2000). Principles of neural science, volume 4. McGraw-Hill New York.

Karuei, I., MacLean, K. E., Foley-Fisher, Z., MacKenzie, R., Koch, S., and El-Zohairy, M. (2011). Detecting vibrations across the body in mobile contexts. In Proc. of the SIGCHI Conference on Human Factors in Computing Systems, pages 3267-3276.

Lira, W., Alves, R., Costa, J., Pessin, G., Galvao, L., Cardoso, A., and De Souza, C. (2014). A visual-analytics system for railway safety management. Computer Graphics and Applications, IEEE, 34(5):52-57.

Panorgias, A., Kulikowski, J. J., Parry, N. R., McKeefry, D. J., and Murray, I. J. (2012). Phases of daylight and the stability of color perception in the near peripheral human retina. Journal of vision, 12(3):1.

Pervic, F. H., Kosnik, W. D., McLin, L. N., Dennis, R. L., and Goetti, B. P. (2005). The visibility of point sources as a function of background luminance, target luminance, eccentricity, wavelength, and flicker rate. Technical report, DTIC Document.

Sivak, M. (1998). The influence of sun loading on the visibility of clear-lens turn signals.

Wogalter, M. S., Kalsher, M. J., Frederick, L. J., and Magurno, A. B. (1998). Hazard level perceptions of warning. Int. Journal of Cognitive Ergonomics, 2(1-2):123-143. 